\title{
Article
}

Subscriber access provided by University of East Anglia Library

\section{Mono- Versus Bicyclic Carbene Metal Amide Photoemitters: Which Design Leads to Best Performance?}

Florian Chotard, Vasily Sivchik, Mikko Linnolahti, Manfred Bochmann, and Alexander S. Romanov

Chem. Mater., Just Accepted Manuscript • DOI: 10.1021/acs.chemmater.0c01769 • Publication Date (Web): 22 Jun 2020

Downloaded from pubs.acs.org on June 25, 2020

\section{Just Accepted}

"Just Accepted" manuscripts have been peer-reviewed and accepted for publication. They are posted online prior to technical editing, formatting for publication and author proofing. The American Chemical Society provides "Just Accepted" as a service to the research community to expedite the dissemination of scientific material as soon as possible after acceptance. "Just Accepted" manuscripts appear in full in PDF format accompanied by an HTML abstract. "Just Accepted" manuscripts have been fully peer reviewed, but should not be considered the official version of record. They are citable by the Digital Object Identifier (DOI®). "Just Accepted" is an optional service offered to authors. Therefore, the "Just Accepted" Web site may not include all articles that will be published in the journal. After a manuscript is technically edited and formatted, it will be removed from the "Just Accepted" Web site and published as an ASAP article. Note that technical editing may introduce minor changes to the manuscript text and/or graphics which could affect content, and all legal disclaimers and ethical guidelines that apply to the journal pertain. ACS cannot be held responsible for errors or consequences arising from the use of information contained in these "Just Accepted" manuscripts. 


\title{
Mono- Versus Bicyclic Carbene Metal Amide Photoemitters: Which Design Leads to Best Performance?
}

\author{
Florian Chotard, ${ }^{1}$ Vasily Sivchik, ${ }^{1}$ Mikko Linnolahti, ${ }^{2 *}$ Manfred Bochmann,,${ }^{*}$ and Alexander S. \\ Romanov ${ }^{1 *}$ \\ ${ }^{1}$ School of Chemistry, University of East Anglia, Earlham Road, Norwich, NR4 7TJ, UK; \\ ${ }^{2}$ Department of Chemistry, University of Eastern Finland, Joensuu Campus, FI-80101 Joensuu, Finland
}

\begin{abstract}
New luminescent "carbene-metal-amide" (CMA) $\mathrm{Cu}, \mathrm{Ag}$ and Au complexes based on monocyclic (C6) or bicyclic six-ring (BIC6) cyclic (alkyl)(amino)carbene ligands illustrates the effects of LUMO energy stabilization, conformational flexibility, excited state energy and geometry on the photoluminescent properties, leading to $100 \%$ luminescence quantum yields, short excited state lifetimes $\mathrm{Cu}>\mathrm{Au}>\mathrm{Ag}$ down to $0.5 \mu \mathrm{s}$ and high radiative rates of $10^{6} \mathrm{~s}^{-1}$. Gold complexes with the BIC6 ligand exhibit exceptional photostability under hard and soft UV-light compared with analogous complexes with C5 and C6 carbenes. Steady-state and time-resolved photoluminescence spectroscopy at $298 \mathrm{~K}$ and $77 \mathrm{~K}$ enabled an estimate of the energy levels of the charge transfer (CT) and locally excited (LE) states with singlet and triplet character. A four-state model is applied to describe thermally activated delayed fluorescence (TADF) properties in CMA materials and correlates excited state lifetimes with the energy difference between LE and CT states.
\end{abstract}

- INTRODUCTION. Luminescent coinage metal complexes are an emerging class of photoemitter materials $^{1-16}$ for organic light emitting diode (OLED) technology, which are able to give up to unity quantum yields via phosphorescence or thermally activated delayed fluorescence (TADF). ${ }^{17,18}$ We have reported ${ }^{19-29}$ a new class of highly photoemissive linear, two-coordinate coinage metal complexes, based on cyclic (alkyl)(amino)carbene (CAAC) ligands ${ }^{30-32}$ which combine pronounced $\sigma$-donor and $\pi$-acceptor properties. The ambiphilic nature of CAACs leads to high thermal stability, excellent photophysical characteristics with near-quantitative photoluminescent quantum yields $\left(\Phi_{\mathrm{PL}}\right)$ and very short excited state lifetimes $(<1 \mu \mathrm{s})$; all highly sought-after characteristics for OLED devices. Termed "carbene-metal-amides" (CMAs), these materials have enabled fabrication of OLEDs with external quantum efficiencies (EQEs) of $>25 \%$ with near- $100 \%$ internal quantum efficiencies at practical brightness $(100-1000$ $\mathrm{cd} \mathrm{m}^{-2}$ ) by both solution processing and thermal vapor deposition techniques, ${ }^{24,25,33,34}$ including dendrimer-type ${ }^{35}$ or conformationally flexible amide systems. ${ }^{36}$ This design principle has recently been extended ${ }^{37,38}$ to other types of $\pi$-acceptors, such as mono-, di-amido or cyclic(amino)(aryl)carbenes. ${ }^{39-44}$ Experimental and theoretical studies have highlighted the importance of rotational flexibility of CMAs for photoemission efficiency. At higher torsion angles the $S_{1}-T_{1}$ energy gap can verge on zero, which facilitates inter-system crossing and enables luminescence with sub-microsecond lifetimes..$^{24,45-48}$

Torsional flexibility makes these systems highly susceptible to steric effects. Studies so far have concentrated on adducts of 5-ring CAACs. Here we focus on CMA complexes with six-membered monocyclic (C6 $)^{49}$ and bicyclic $(\mathrm{BIC6})^{50,51}$ carbenes, as examples of ligands with flexible and rigid saturated backbones, respectively. These carbenes are more ambiphilic than 5-membered CAACs (C5, Chart 1), ${ }^{30-32}$ while having different steric congestion around the metal. The aim was to explore the relative importance of these molecular design parameters on photoluminescent properties.

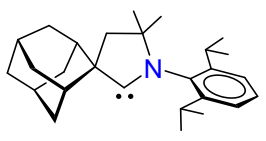

C5

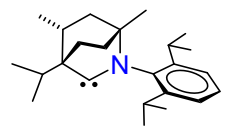

BIC6

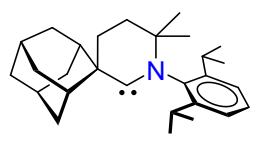

C6
Chart 1. Molecular structures of carbenes.

\section{- RESULTS AND DISCUSSION}

Synthesis and structure. The chloride complexes M1 and M3 with adamantyl-substituted 6-ring (C6) and bicyclic isopropyl(amino)carbene (BIC6) ligands, respectively, (Scheme 1) were prepared as described for Au1 (Supporting Information). ${ }^{50,51}$ The carbazolate $(\mathrm{Cz})$ derivatives $\mathbf{M} 2$ and $\mathbf{M 4}$ were obtained in high yield following our previously published procedure (Scheme 1, see Supporting Information). ${ }^{24}$ All chloride complexes M1 and M3 are white solids while carbazolate complexes are off-white $(\mathrm{M}=\mathrm{Cu})$ or yellow $(\mathrm{M}=\mathrm{Au})$. The complexes possess good solubility in aromatic and polar non-protic solvents like dichloromethane, THF, and acetone, and moderate solubility in acetonitrile. As solids M1-M4 are stable in air for several months. M4 complexes show superior photostability compared with $\mathbf{M 2}$ if irradiated with hard UV-light at $290 \mathrm{~nm}$ in all media (Figures S27-S40). 

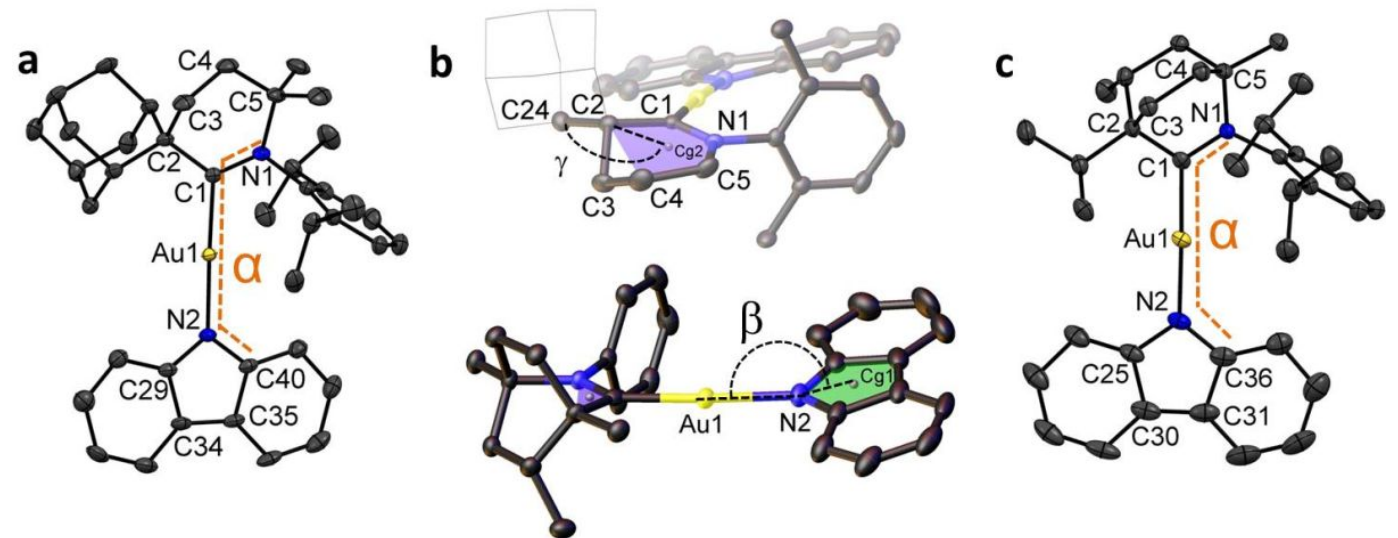

Figure 1. The crystal structures of carbene metal amides Au2 (a) and Au4 (c), including side views of Au2 and Au4 showing the conformations adopted by the amide ligands. Ellipsoids are shown at the 50\% level. Hydrogen atoms are omitted for clarity. Angle $\beta$ is for $\mathrm{C} 2-\mathrm{C} 24-\mathrm{Cg} 1$, where $\mathrm{Cg} 1=$ centroid of the $\mathrm{C} 2, \mathrm{C} 2, \mathrm{~N} 1, \mathrm{C} 5, \mathrm{C} 4$ plane.

Table 1. Selected distances $[\AA]$, angles $\left[^{\circ}\right]$, metal buried volumes $\left(\mathrm{V}_{\mathrm{bur}}\right),{ }^{13} \mathrm{C}$ NMR chemical shift for the carbene atom and formal electrode reduction potentials $\left(E_{\mathrm{red}}\right.$ peak position $E_{\mathrm{p}}$ for irreversible and $E_{1 / 2}$ for quasi-reversible processes $(*), V$, vs. FeCp $\left.\mathrm{p}_{2}\right)$ for complexes M2 and M4.

\begin{tabular}{cccccccc}
\hline M & $\mathrm{C} 1 \cdots \mathrm{N} 2, \AA$ & $\mathrm{C} 1-\mathrm{M}-\mathrm{N} 2{ }^{\circ}{ }^{\circ}$ & $\alpha,{ }^{\circ} \mathrm{a}$ & $\beta,{ }^{\circ}, b$ & $\mathrm{~V}_{\text {bur }}, \%$ & $\delta\left({ }^{13} \mathrm{C}:\right), \mathrm{ppm}$ & $E_{\mathrm{red}}(V)$ \\
\hline Cu2 & $3.746(5)$ & $176.1(1)$ & $32.9(4)$ & $171.6(1)$ & 53.9 & 267.1 & -2.90 \\
Au2 & $4.025(7)$ & $176.9(2)$ & $22.2(5)$ & $178.2(1)$ & 51.4 & 254.8 & $-2.54^{*}$ \\
Cu4 & $3.749(1)$ & $176.0(1)$ & $19.6(1)$ & $167.6(1)$ & 48.0 & 260.2 & $-2.96^{*}$ \\
Ag4 & $4.142(4)$ & $175.6(1)$ & $22.0(3)$ & $167.3(1)$ & 45.0 & 269.2 & $-2.91 *$ \\
Au4 & $4.008(3)$ & $176.2(1)$ & $19.5(3)$ & $168.1(1)$ & 45.8 & 247.6 & $-2.77^{*}$ \\
\hline
\end{tabular}

${ }^{a}$ torsion angle $(\alpha) \mathrm{N} 1-\mathrm{C} 1-\mathrm{N} 2-\mathrm{C} 40$ for $\mathrm{C} 6$ and $\mathrm{N} 1-\mathrm{C} 1-\mathrm{N} 2-\mathrm{C} 36$ for BIC6; ${ }^{b} \mathrm{Cg} 1$ centroid for the carbazolate fivemembered ring (N2,C29,C34,C35,C40 for M2 and N2,C25,C30,C31,C36 for M4 complexes).

The photostability increases in the order of Cu4 $<<$ Ag4 $<<$ Au4 under soft UV-light (400 nm) with no degradation for complex Au4 in a zeonex matrix (Figures S35, S37 and S39). Such superior stability for gold complexes with BIC6 carbene ligand parallels well with recent results reported by Bertrand et al. ${ }^{51}$ All complexes have been characterized by elemental analysis, high-resolution MS, ${ }^{1} \mathrm{H}$ and ${ }^{13} \mathrm{C}$ NMR spectroscopy. Both chloride and carbazolate complexes M1-M4 show 4-7 ppm downfield shift for the ${ }^{13} \mathrm{C}$ carbene-C resonance following the trend in increasing ambiphilic properties of the carbenes $\mathrm{C}^{6 \mathrm{a}, 10}<$ BIC6 $<$ C6 $($ Table 1$)$.
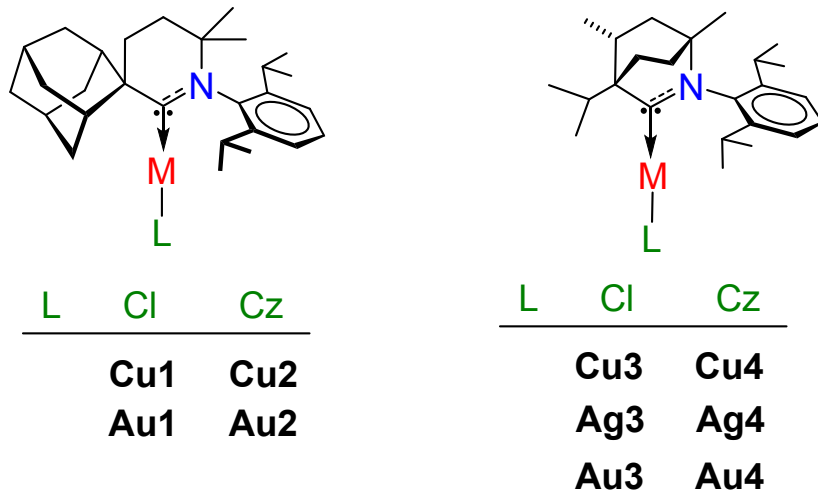

Scheme 1. Molecular structures of the carbene metal amide complexes.

X-ray crystallography (Figure 1) confirmed the linear monomeric structure and the lack of close intermolecular contacts (Table 1 and S1). The donor-acceptor distances $\mathrm{C} 1 \cdots \mathrm{N} 2$ for $\mathrm{M} 2$ and $\mathbf{M} 4$ reflect the increase in covalent radii in the order $\mathrm{Cu}<\mathrm{Au}<\mathrm{Ag} .{ }^{52}$ The torsion angle $(\alpha)$ between $\mathrm{Cz}$ and CAAC ligand planes is $2-13^{\circ}$ more twisted for $\mathbf{M 2}$ compared with M4 complexes (Table 1). Unlike M2, in complexes $\mathrm{M} 4$ the $\mathrm{Cz}-\mathrm{N}$ atom is pyramidal (tilt angle $\beta \approx$ $168^{\circ}$, see Fig. 1b) due to packing effects. The C6 ring in M1 and M2 adopts a high-energy half-chair conformation, which places the adamantyl group on one side of the N1-C1-C2C4-C5 plane, opposite to the C3 atom (Figure 1b). This contrasts with CMA complexes of five-membered C5, where the ligand plane bisects the adamantyl group. ${ }^{24}$

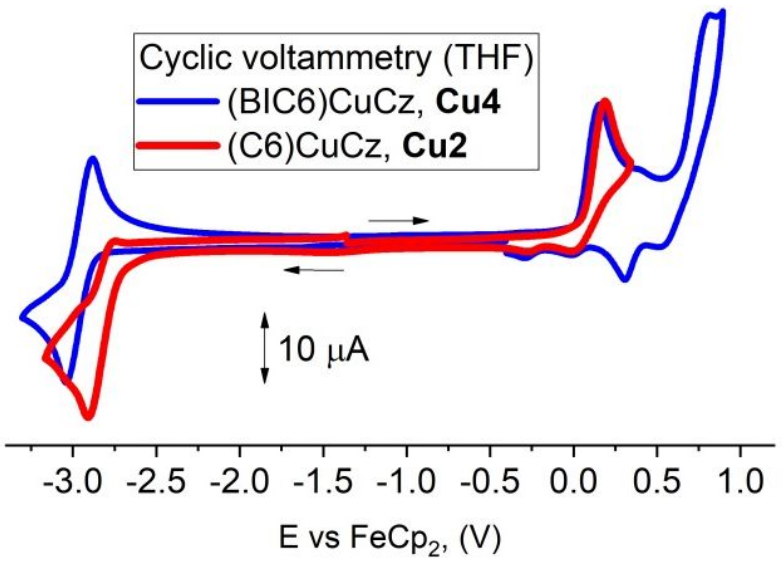

Figure 2. Overlap of the full range cyclic voltammograms for $\mathrm{Cu} 2$ (red) and $\mathrm{Cu} 4$ (blue) complexes. Recorded using a glassy carbon electrode in THF solution $(1.4 \mathrm{mM})$ with $\left[n \mathrm{Bu}_{4} \mathrm{~N}\right] \mathrm{PF}_{6}$ as supporting electrolyte $(0.13 \mathrm{M})$, scan rate $0.1 \mathrm{Vs}^{-1}$. 


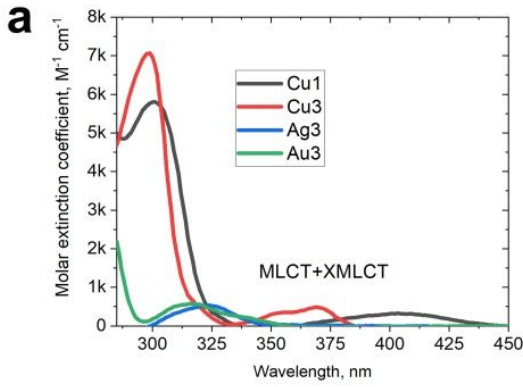

b

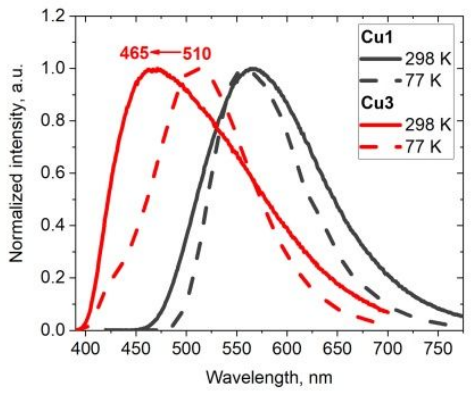

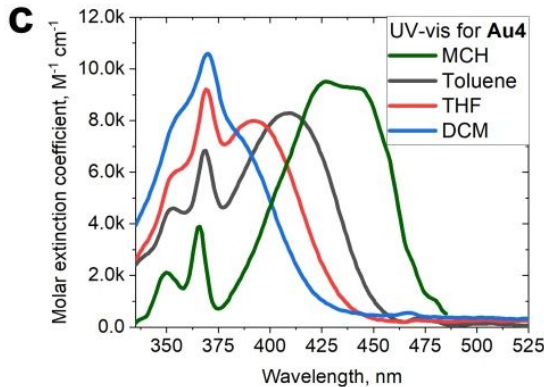

d

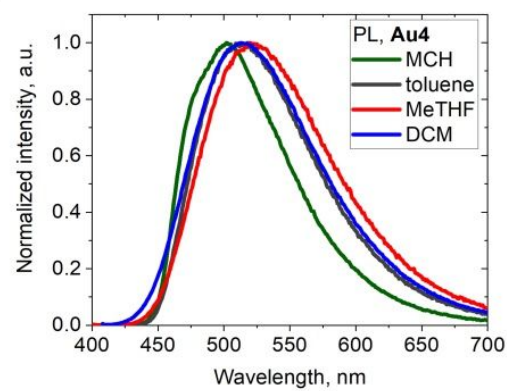

e

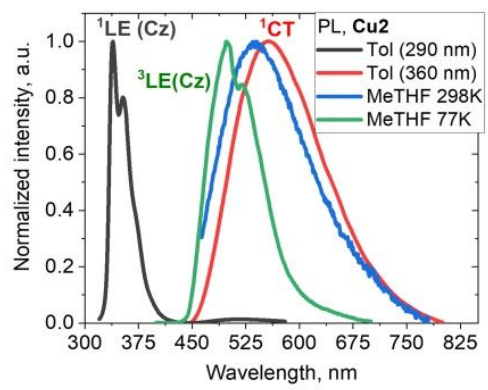

f

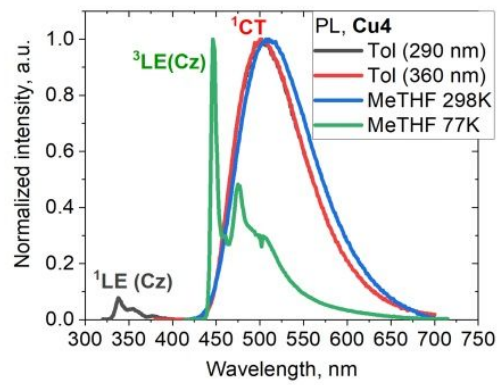

Figure 3. (a) UV-vis spectra of the chloride complexes Cu1 and M3 complexes in THF solution (298 K); (b) PL spectra of the chloride complex Cu1 and Cu3 in a crystalline state at 298 and 77 K; UV-vis (c) and emission (d) spectra for Au4 in various solvents; Emission spectra for $\mathbf{C u 2}$ (e) and $\mathbf{C u 4}$ (f) in toluene and MeTHF solution (excited at 290 (black) and $360 \mathrm{~nm}$ (red, green and blue) at 298 and 77K.

Cyclic voltammetry of the carbazolates M2 and M4 in THF (Table 1 and S2, Figures S1-S4) shows two irreversible oxidation waves (no corresponding reduction waves are seen upon reversing the scan direction) with $E_{p}$ varying in a small range $(0.25 \pm 0.1$ and $0.88 \pm 0.07 \mathrm{~V}$, see Table S2) indicative of a carbazole-localized process and consistent with previous reports on CMA complexes. ${ }^{21-25}$ Au2 and M4 complexes show a quasi-reversible reduction process with a back-peak upon reoxidation and an $i_{\mathrm{pa}} / i_{\mathrm{pc}}$ ratio in the range of $0.5-0.84$ (at 100 $\mathrm{mV} \mathrm{s}^{-1}$ ), which is less than unity - the ideal value for a reversible couple (see Table 1). Complex Cu2 shows an irreversible reduction process. The $E_{1 / 2}$ value for the Au4 reduction process $(-2.77 \mathrm{~V})$ exhibits a shift of $230 \mathrm{mV}$ to a lower potential compared with Au2 $(-2.54 \mathrm{~V})$. This indicates a higher electrophilicity for the C6 compared with the BIC6 ligand and results in a stabilization of the lowest unoccupied molecular orbital (LUMO) of M2 by $0.15-0.2 \mathrm{eV}$ (for example see $\mathbf{C u 2} / \mathbf{C u 4}$, Figure 2). This explains the ca. $0.2 \mathrm{eV}$ smaller band gap for M2 compared with M4 and affects the absorption and emission properties, vide infra.

\section{Photophysical properties and theoretical} considerations.

Chloride complexes. The UV-vis spectra for the chloride complexes M1 and M3 (Figure 3a, Figure S5 and Table S3) show a broad and weak low-energy band in the range of $320-450 \mathrm{~nm}$. This is tentatively assigned to a combination of MLCT and XMLCT transitions, in agreement with theoretical calculations (ESI, Table S5). ${ }^{21-25,53,54}$ The photoluminescence (PL) properties of the chlorides $\mathbf{C u 1}$ and M3 crystals have been studied at 298 and 77K (Figure S5-S9 with data collected in the Table S4, ESI). The copper complexes $\mathbf{C u 1}$ and $\mathbf{C u 3}$ show yellow and sky-blue PL with quantum yields $\left(\Phi_{\mathrm{PL}}\right)$ of 40 and 14\%, respectively. Complexes M3 exhibit a 10$50 \mathrm{~nm}$ red-shift of the PL profile upon cooling to $77 \mathrm{~K}$, whereas the PL for Cu1 shows no shift with only slight narrowing (Figure 3b, S6-S9). The excited state lifetime decreases from $\mathbf{C u} 3$ to $\mathbf{A u 3}$ due to an increase in the spin orbit coupling coefficients $\left(\mathrm{H}_{\mathrm{so}}\right)$ which facilitates the intersystem crossing and increases the radiative rate constant $k_{r}$ by one order of magnitude (Table S4). The excited state lifetime increases up to 3 times for $\mathbf{C u 1 / 3}$ and Au3 and 8 times for Ag3 upon cooling to $77 \mathrm{~K}$ (Table S4). Such temperature dependent behavior is similar to analogous $\quad\left({ }^{\mathrm{Ad}} \mathrm{C} 5\right) \mathrm{CuCl}$ complexes. Theoretical calculations show a large energy difference between $S_{1}$ and $T_{1}$ states $(0.4-0.6 \mathrm{eV}$, see Table $\mathrm{S} 8)$, supporting phosphorescence for chlorides $\mathbf{C u 1}$ and M3.

Carbazolate complexes. The lowest energy absorption in the UV-vis spectra of the carbazolate complexes M2 and M4 (Figure 3c, S10, S11 and Table S3) is due to metal-mediated charge-transfer (L(M)LCT) from carbazole to carbene. Increasing the solvent polarity from methylcyclohexane (MCH, $\varepsilon=2.02)$ to $\mathrm{CH}_{2} \mathrm{Cl}_{2}(\varepsilon=$ 8.93) results in a blue-shift of the L(M)LCT band by $c a$. $60 \mathrm{~nm}$ for all $\mathrm{Cz}$ complexes (Figures 3c, S10 and S11). The intensity of the CT band decreases in the series $\mathrm{Au}>$ $\mathrm{Cu} \gg>\mathrm{Ag}$ with the lowest value for Ag4 $\left(\varepsilon=1700 \mathrm{M}^{-1}\right.$ $\mathrm{cm}^{-1}$ ) and follows the decrease in the HOMO/LUMO overlap integral (Table S6, ESI). The large negative solvatochromism of the UV-vis spectra and the negligible positive solvatochromism for the photoluminescence (PL, Figures $3 \mathrm{c}$ and $3 \mathrm{~d}$ ) are in line with a large ground-state dipole moment and a smaller excited state dipole in the opposite direction, supported by DFT calculations (Table S7).

The PL properties of complexes M2 and M4 (Table 2; Figures 3d-f, 6, S12-S21) were measured at $298 \mathrm{~K}$ and $77 \mathrm{~K}$. In solution compounds M2 show yellow luminescence, whereas M4 give green emissions, in line 
with the higher electrophilicity (LUMO stabilization) of $\mathrm{C} 6$ and consistent with the $0.2 \mathrm{eV}$ larger HOMO-LUMO band gap (ESI, Table S2). Toluene solutions of $\mathbf{C u} 2$ at $298 \mathrm{~K}$ show negligible charge transfer (CT) emission $\left(\Phi_{\mathrm{PL}}\right.$ $3.6 \%$ ), while Au2 shows a surprisingly low (for gold) $\Phi_{\mathrm{PL}}$ of only $21.8 \%$. This poor luminescence of compounds $\mathbf{M 2}$ is in startling contrast with the emissions of analogous 5-ring CAAC complexes $\left(\Phi_{\mathrm{PL}} 74-98 \%\right),{ }^{21-25}$ and even more with the BIC6 complexes Cu4 and Au4, both of which show $100 \%$ quantum yields. The $\Phi_{\mathrm{PL}}$ of the silver analogue Ag4 (82\%) compares favorably with the analogous 5-ring CAAC carbene $\left(\Phi_{\mathrm{PL}} 74 \% \text { in toluene }\right)^{34}$ and six-ring monoamido carbene $\left(\Phi_{\mathrm{PL}} 6 \%\right.$ in MeTHF) silver complexes. ${ }^{43}$

On one hand, the steric protection of the metal center in CMA complexes could be seen as an important factor to rationalize the observed $\Phi_{\mathrm{PL}}$ values in solution. We calculated the buried volumes $\left(V_{\text {bur }}, \%\right)$ of adamantyl-C5, C6 and iso-propyl BIC6 carbene ligands using the SambVca2.1 program $^{55}$ (Table S1, Figure 4). For example, $V_{\text {bur }}$ of the ligands increases in the order $\mathbf{C u} 4$ $(48 \%)<(\mathrm{C} 5) \mathrm{Cu}(\mathrm{Cz}) \quad(51.4 \%)<\mathrm{Cu} 2 \quad(53.9 \%)$ contrariwise with the observed $\Phi_{\mathrm{PL}}$ values in toluene $\mathbf{C u} 4$ $(100 \%)>(\mathrm{C} 5) \mathrm{Cu}(\mathrm{Cz})(74 \%)>\mathrm{Cu} 2(3.6 \%)$. Realization of a copper-based emitter with $100 \% \Phi_{\mathrm{PL}}$ but small $V_{\text {bur }}$ parameter indicates that steric protection of the metal center is only one of many parameters to consider. ${ }^{24,37} \mathrm{On}$ the other hand, excited state distortion has been identified as one of the main reasons for the significant luminescence quenching in solutions of mononuclear metal complexes, ${ }^{56-58}$ with geometry change facilitating electronic to vibrational energy conversion and radiationless decay. ${ }^{59}$ Bicyclic carbenes are noted for their more rigid structure compared with monocyclic analogues. ${ }^{60,61} \mathrm{We}$ calculated the energy barrier between two conformers for C6 $(38.5 \mathrm{~kJ} / \mathrm{mol})$ and C5 $(3 \mathrm{~kJ} / \mathrm{mol})$ carbene ligands (see mp4 video, Supporting Information), whereas no conformers are observed for the BIC6 ligand. This indicates that complexes with C6 monocyclic carbene have more conformational freedom enabling structural promiscuity compared with simple elbowshaped conformers for $\mathrm{C} 5$ monocyclic and rigid BIC6carbene ligands. Therefore, the increasing $\Phi_{\mathrm{PL}}$ values of complexes with monocyclic-C6, monocyclic-C5 and bicyclic BIC6 carbene ligands may at least in part be due to the differences in ring flexibility. ${ }^{62}$

Linear coinage metal complexes may experience Renner-Teller or bending geometrical distortion ${ }^{63,64}$ resulting in significant nonradiative losses. Our theoretical calculations show that the $\mathrm{S}_{0}$ geometry is in good agreement with the crystal structure for the linear complexes of interest, $\mathbf{C u} 2$ and Cu4 (Figure 4). The $\mathrm{S}_{1}$ state largely retains linear geometry for both $\mathbf{C u} 2$ and $\mathrm{Cu} 4$, whereas the torsion angle between carbene and amide ligands $(\alpha=\mathrm{N} 1-\mathrm{C} 1-\mathrm{N} 2-\mathrm{C} 40$ for $\mathrm{C}-6$ and N1-C1N2-C36 for BIC6) is $49^{\circ}$ for $\mathbf{C u} 2$ and $88^{\circ}$ for $\mathbf{C u 4}$. This may be explained with a smaller buried volume for $\mathbf{C u} 4$ compared with $\mathbf{C u} 2$ unlocking the relative rotation of the carbene and amide moieties. The optimized geometry for $\mathrm{T}_{1}$ has $\mathrm{C} 1-\mathrm{Cu}-\mathrm{N} 2$ angles of $164^{\circ}$ and $171^{\circ}$ for $\mathbf{C u} 2$ and $\mathrm{Cu} 4$, respectively. This shows a stronger Renner-Teller distortion for the monocyclic complex Cu2, while the torsion angle is ca. $10^{\circ}$ larger compared with the ground
$\mathrm{S}_{0}$ state geometry for both complexes (Figure 4). This shows the tendency of $\mathbf{C u} 4$ to retain a linear geometry, similar to the previously reported $\left({ }^{\mathrm{Ad}} \mathrm{C} 5\right) \mathrm{Cu}(\mathrm{Cz})$ complex, unlike Cu2 with its monocyclic-C6 carbene ligand. The decrease in Renner-Teller distortion in the excited states parallels the decrease in nonradiative rates, $k_{\mathrm{nr}}\left(\mathrm{s}^{-1}\right)=$ $7.0 \times 10^{5}(\mathbf{C u 2})>1.3 \times 10^{5}\left({ }^{\mathrm{Ad}} \mathrm{C} 5\right) \mathrm{Cu}(\mathrm{Cz})^{35}>0.03(\mathbf{C u} 4)$.
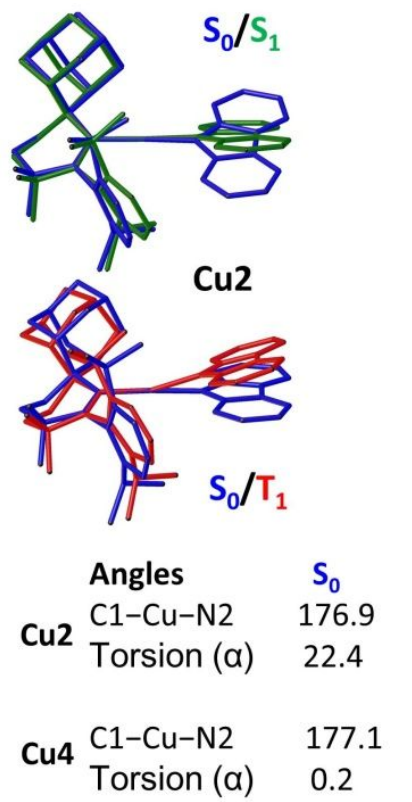

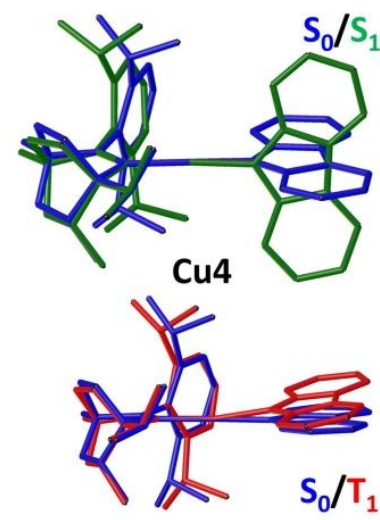

\begin{tabular}{ccl}
\multicolumn{1}{c}{$\mathrm{S}_{1}$} & $\mathrm{~T}_{1}$ & XRD \\
174.5 & 164.1 & $\mathbf{1 7 6 . 1 ( 1 )}$ \\
49.1 & 31.2 & $\mathbf{3 2 . 9 ( 4 )}$ \\
& & \\
174.6 & 171.1 & $\mathbf{1 7 6 . 0 ( 1 )}$ \\
88.4 & 9.3 & $\mathbf{1 9 . 6 ( 1 )}$
\end{tabular}

Figure 4. Superposition of the $S_{0}$ and $S_{1}$ (top), and $S_{0}$ and $T_{1}$ (middle) geometries for complexes $\mathrm{Cu} 2$ and $\mathrm{Cu} 4$ determined by theoretical calculations. Bottom: Calculated angles and single crystal X-ray diffraction (XRD) data where torsion angle $(\alpha)$ is $\mathrm{N} 1-\mathrm{C} 1-\mathrm{N} 2-\mathrm{C} 40$ for $\mathrm{C} 6$ and N1-C1-N2-C36 for BIC6.

We recorded solution PL spectra in MeTHF at room temperature and $77 \mathrm{~K}$ to measure the energy of the ${ }^{l} C T$ and ${ }^{3} L E$ states, respectively (Figure $3 \mathrm{e}, \mathrm{f}$ ). For all $\mathbf{M 2}$ and M4 complexes the $\mathrm{Cz}{ }^{3} L E$ triplet state is $0.1-0.3 \mathrm{eV}$ higher than the ${ }^{I} C T$ state (Table 2, Figure 5 for Au2), leading to negative energy gap values $\triangle E\left({ }^{1} C T-{ }^{3} L E\right)$ which increase in the order $\mathrm{Cu}<\mathrm{Ag}<\mathrm{Au}$. Next, we measured solution PL spectra at varied excitation wavelengths $(290-440 \mathrm{~nm})$ for all complexes in toluene (Figures S12b, S15b, S18b, S20b, S21b) looking for the higher lying excited states. Indeed, high energy excitation $(280-310 \mathrm{~nm})$ leads to emission at $c a .340 \mathrm{~nm}(3.75 \mathrm{eV})$ originating from the carbazole local excited state $\left({ }^{1} L E\right)$ together with charge-transfer ${ }^{I} C T$-emission from the L(M)LCT. We have described Cz-based fluorescence $\left({ }^{1} L E\right)$ for similar $\mathrm{Cz}$-dendrimer complexes with the fivemembered C5 ligand. ${ }^{35}$ Let us consider Cu2 $\left(\Phi_{\mathrm{PL}} 3.6 \%\right)$, Au2 $\left(\Phi_{\mathrm{PL}} 22 \%\right)$ and $\mathbf{C u} 4\left(\Phi_{\mathrm{PL}} 100 \%\right)$ as representative examples to show the interplay between CT and LE states (for the emission-excitation maps see Figure S24). The $\mathrm{Cz}$ $\left({ }^{1} L E\right)$ emission is a major radiative pathway for monocyclic $\mathbf{C u} 2$ (Figure 3e), whereas it is hardly detectable for the bicyclic analogue Cu4 (Figure 3f), where the ${ }^{I} C T$ emission dominates at all excitation wavelengths (Figures S18b). The gold Au2 complex 
shows intense ${ }^{l} L E$ and ${ }^{l} C T$ emission and is therefore convenient to compare with our theoretical calculations.

Table 2. Photophysical properties of copper, silver and gold complexes M1-M4 as neat films, in Zeonex matrix (dopant level 1 weight-\%) and in toluene solution (excited at $360 \mathrm{~nm}$ in all media).

\begin{tabular}{|c|c|c|c|c|c|c|c|c|}
\hline & $\begin{array}{c}\lambda_{\mathrm{em}} \\
(\mathrm{nm})\end{array}$ & $\begin{array}{c}\tau \\
(\mu \mathrm{s})^{f}\end{array}$ & $\Phi_{\mathrm{PL}}(\%)^{b}$ & $\begin{array}{c}k_{\mathrm{r}}\left(10^{5}\right. \\
\left.\mathrm{s}^{-1}\right)^{c}\end{array}$ & $\begin{array}{c}k_{\mathrm{nr}}\left(10^{5}\right. \\
\left.\mathrm{s}^{-1}\right)^{d}\end{array}$ & ${ }^{1} \mathrm{CT} /{ }^{\beta} \mathrm{LE} /{ }^{1} \mathrm{LE}(\mathrm{eV})^{e}$ & $\begin{array}{c}\lambda_{\mathrm{em}}(\mathrm{nm}, \\
77 \mathrm{~K})\end{array}$ & $\tau(\mu \mathrm{s}, 77 \mathrm{~K})$ \\
\hline \multicolumn{9}{|c|}{ Toluene $^{a}$} \\
\hline $\mathbf{C u 2}$ & 556 & 1.37 & 3.6 & 0.2 & 7.0 & $2.68 / 2.78 / 3.79$ & - & - \\
\hline Au 2 & 570 & 0.26 & 21.8 & 8.3 & 30 & $2.64 / 2.95 / 3.79$ & - & - \\
\hline $\mathrm{Cu} 4$ & 502 & 3.3 & 100 & 3.0 & $<0.03$ & $2.78 / 2.82 / 3.76$ & - & - \\
\hline Ag4 & 526 & 0.5 & 82 & 16.4 & 3.6 & $2.74 / 2.90 / 3.76$ & - & - \\
\hline Au4 & 512 & 1.1 & 100 & 9.1 & $<0.05$ & $2.80 / 2.95 / 3.75$ & - & - \\
\hline \multicolumn{9}{|l|}{ Neat $^{a}$} \\
\hline $\mathrm{Cu2}$ & 557 & 16 & 10 & 0.06 & 0.5 & $2.68 /-1-$ & 548 & $44.8\left(100 \%{ }^{3} \mathrm{CT}\right)$ \\
\hline Au 2 & 498 & 0.66 & 30 & 4.5 & 10.6 & $2.85 / 2.85 /-$ & 485 & $\begin{array}{c}29.0\left(85 \%{ }^{3} \mathrm{CT}\right), 78.0(15 \% \\
\left.{ }^{3} \mathrm{LE}\right)\end{array}$ \\
\hline $\mathrm{Cu} 4$ & 488 & 4 & 23 & 0.5 & 1.9 & $2.86 / 2.80 /-$ & 451,549 & $\begin{array}{c}43.7\left(41 \%{ }^{3} \mathrm{CT}\right), 7199 \\
\left(59 \%{ }^{3} \mathrm{LE}\right)\end{array}$ \\
\hline Ag4 & 500 & 0.58 & 18 & 3.1 & 14.1 & $2.87 / 2.85 /-$ & 456,482 & $\begin{array}{c}46.9\left(68 \%{ }^{3} \mathrm{CT}\right), 168(32 \% \\
\left.{ }^{3} \mathrm{LE}\right)\end{array}$ \\
\hline Au4 & 486 & 0.92 & 47 & 5.1 & 5.7 & $2.92 /-1-$ & 479 & $\begin{array}{c}30.7\left(59 \%{ }^{3} \mathrm{CT}\right), 63.4(41 \% \\
\left.{ }^{3} \mathrm{LE}\right)\end{array}$ \\
\hline \multicolumn{9}{|c|}{$1 \%$ Zeonex matrix $^{a}$} \\
\hline $\mathrm{Cu} 2$ & 519 & 9.8 & 6 & 0.06 & 0.95 & $2.76\left({ }^{1} \mathrm{CT}\right) / 2.60\left({ }^{3} \mathrm{CT}\right)$ & 546 & $42.6\left(100 \%{ }^{3} \mathrm{CT}\right)$ \\
\hline Au2 & 523 & 1.0 & 54 & 5.4 & 4.6 & $2.68\left({ }^{1} \mathrm{CT}\right) / 2.67\left({ }^{3} \mathrm{CT}\right)$ & 521 & $61.0\left(100 \%{ }^{3} \mathrm{CT}\right)$ \\
\hline $\mathrm{Cu} 4$ & 493 & 5 & 64 & 1.20 & 0.7 & $2.81\left({ }^{1} \mathrm{CT}\right) / 2.71\left({ }^{3} \mathrm{CT}\right)$ & 512 & $\begin{array}{c}58.4\left(78 \%{ }^{3} \mathrm{CT}\right), 107.3 \\
\left(22 \%{ }^{3} \mathrm{LE}\right)\end{array}$ \\
\hline Ag4 & 496 & 0.9 & 84 & 9.3 & 1.7 & $2.85 / 2.88 / 3.78$ & $\begin{array}{l}435,467 \\
494\end{array}$ & $\begin{array}{c}23.5\left(90 \%{ }^{3} \mathrm{CT}\right), 274 \\
\left(10 \%{ }^{3} \mathrm{LE}\right)\end{array}$ \\
\hline Au4 & 490 & 1.3 & 100 & 7.7 & $<0.01$ & $2.85 / 2.91 / 3.78$ & $\begin{array}{l}430,475 \\
499\end{array}$ & $56.0\left(100 \%{ }^{3} \mathrm{CT}\right)$ \\
\hline
\end{tabular}

${ }^{a}$ All films were prepared by drop-casting toluene solutions $(1 \mathrm{mg} / \mathrm{mL})$ onto a hot quartz substrate and annealed for $5 \mathrm{~min} ;{ }^{b}$ Quantum yields $\left(\Phi_{\mathrm{PL}}\right)$ determined using an integrating sphere, see ESI for details; ${ }^{c}$ radiative rate constant $k_{\mathrm{r}}=\Phi / \tau$; ${ }^{d}$ Nonradiative constant $k_{\mathrm{nr}}=(1-\Phi) / \tau$. ${ }^{e}{ }^{1} \mathrm{CT}$ and ${ }^{3} \mathrm{LE}$ energy levels based on the onset of the emission spectra blue edge in MeTHF glasses at 77 $\mathrm{K}$ and $298 \mathrm{~K}$, see Fig S26; ${ }^{f}$ Measured at $\lambda_{\mathrm{em}}(\max , \mathrm{nm})$

The calculated vertical excitation energies $\mathrm{S}_{0} \rightarrow \mathrm{S}_{1}$ and $\mathrm{S}_{0} \rightarrow \mathrm{S}_{5}$ agree well with the UV-vis absorptions in toluene at $415 \mathrm{~nm}$ (ca. $2.99 \mathrm{eV}$, Figure 5) and $306 \mathrm{~nm}$ (ca. $4.04 \mathrm{eV}$ ), respectively. These two vertical transitions are predominately HOMO $\rightarrow$ LUMO $\left(97 \%\right.$ for $\left.\mathrm{S}_{0} \rightarrow \mathrm{S}_{1}\right)$ and $\mathrm{HOMO} \rightarrow \mathrm{LUMO}+3\left(87 \%\right.$ for $\left.\mathrm{S}_{0} \rightarrow \mathrm{S}_{5}\right)$ in character. The $\mathrm{S}_{1}$ state originates from the interligand ${ }^{1} C T$ transition from the carbazole to carbene (vertical) whereas $\mathrm{S}_{5}$ state is a result of intraligand transition $\left({ }^{l} L E\right)$ across the long axis of the carbazole (horizontal). Such a different nature for mutually orthogonal ${ }^{1} C T$ and ${ }^{l} L E$ states could result in slow internal conversion $\left(\mathrm{IC}\right.$, for $\mathrm{S}_{5} \rightarrow \mathrm{S}_{1}$ ). Moreover, the oscillator coefficients $(f)$ for the high energy $\mathrm{S}_{0} \rightarrow \mathrm{S}_{5}$ transitions is one quarter of the pure HOMO $\rightarrow$ LUMO transition (0.1779). Therefore, the high $f$ values for $\mathrm{S}_{0} \rightarrow \mathrm{S}_{1}$ and $\mathrm{S}_{0} \rightarrow \mathrm{S}_{5}$ transitions and the different nature of the mutually orthogonal ${ }^{l} C T$ and ${ }^{l} L E$ states may explain the significant competing fluorescence from the carbazole moiety. This phenomenon results in reduced $\Phi_{\mathrm{PL}}$ values for the TADF luminescence, which is even more pronounced for the $\mathbf{C u} \mathbf{2}$ analog (Table 2). Population of ${ }^{1} L E$ state is consistent with a four state-model recently proposed by de Silva et al. ${ }^{67}$ and the spin-vibronic model developed by Penfold et al. ${ }^{65,66}$ Therefore, molecular design is a highly effective tool to develop materials showing multiple luminescence, which one may see as anti-Kasha behavior and was reported not only for coinage metal complexes but also for $\mathrm{Pt}(\mathrm{II})$, Ir(III), $\mathrm{Ru}(\mathrm{II}), \mathrm{Os}(\mathrm{II}), \operatorname{Re}(\mathrm{I})$ and other materials. ${ }^{68-72}$

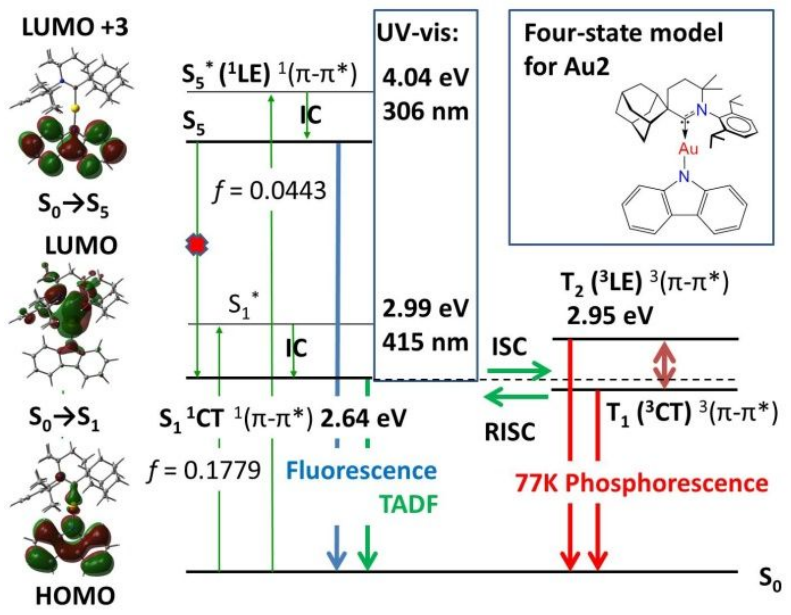

Figure 5. Four excited states model for complex Au2. Internal conversion (IC) from $\mathrm{S}_{5}$ to $\mathrm{S}_{1}$ is significantly slowed down due to mutual orthogonality between $S_{5}$ and $S_{1}$ states. 
In neat or Zeonex films the majority of the complexes display green to sky-blue luminescence, while in polystyrene matrices (PS, 1 weight-\% dopant level) blue PL is observed, which is blue-shifted by up to $70 \mathrm{~nm}$ compared to the emissions in toluene (Table 2; Figures 3 and S12-S21). 

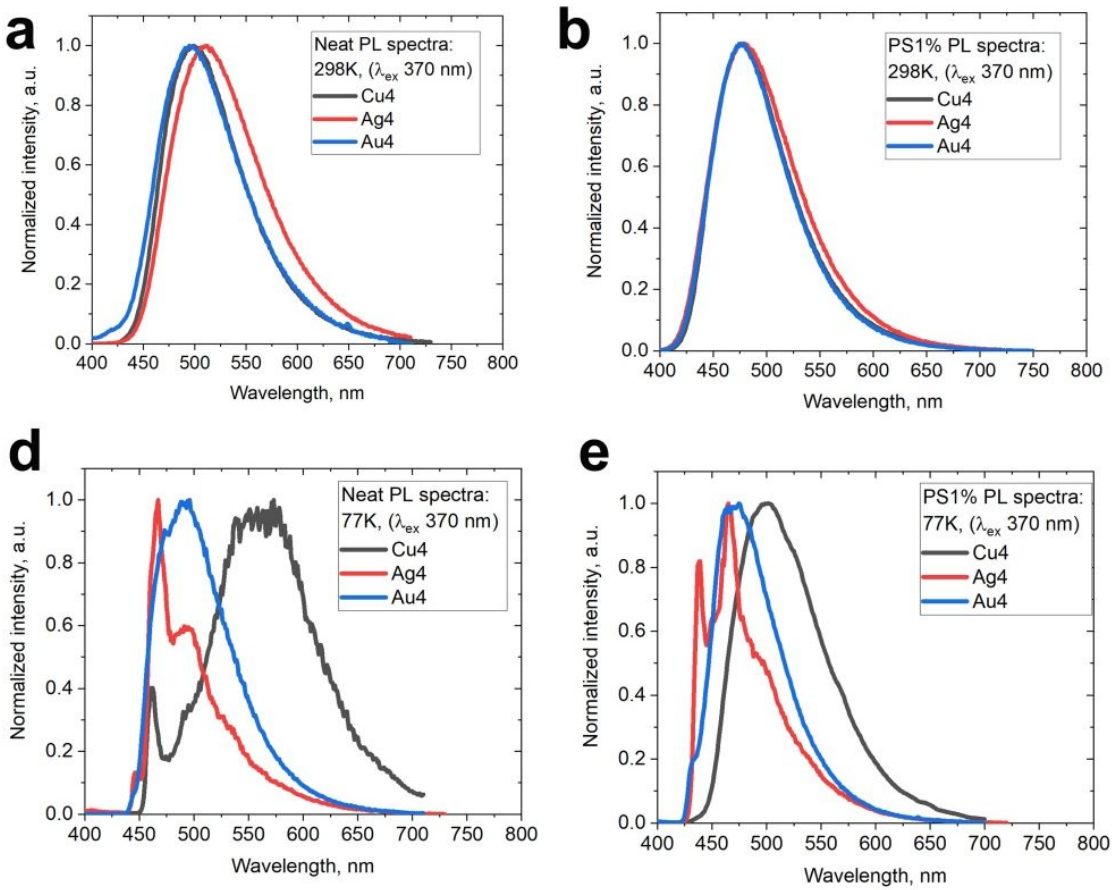

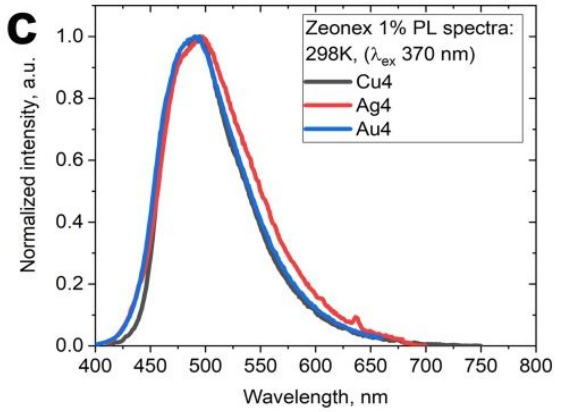

f

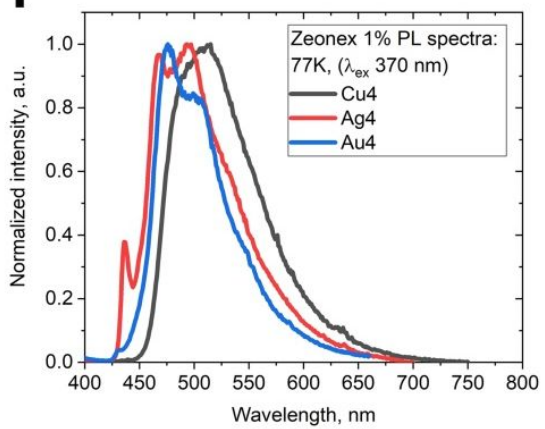

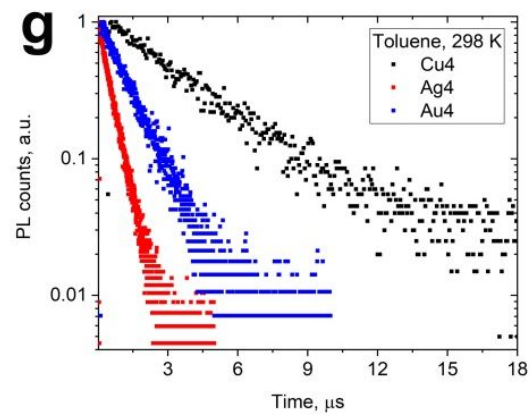

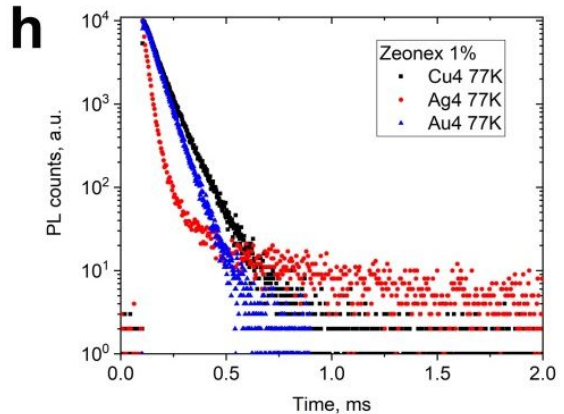

Figure 6. PL spectra of CMA complexes M4 as neat films (a), 1 wt-\% dopant in PS (b), 1 wt-\% dopant in Zeonex (c) at $298 \mathrm{~K}$ and $77 \mathrm{~K}$ (d, e, f). Photoluminescence decay profiles for complexes M4 in toluene at $298 \mathrm{~K}$ (g) and $1 \mathrm{wt}-\%$ dopant in Zeonex at $77 \mathrm{~K}(\mathrm{~h})$, excited at $370 \mathrm{~nm}$ and measured at $\lambda_{\mathrm{em}}(\max , \mathrm{nm})$.

The only exception is complex $\mathbf{C u 2}$, which shows yellow $\mathrm{PL}$ as a neat film, red-shifted by $59 \mathrm{~nm}$ relative to its gold analogue Au2. The solid-state $\Phi_{\mathrm{PL}}$ values for M2 and M4 show an up to two-fold increase on dilution, from 10 $47 \%$ for neat films to $22-100 \%$ in a $1 \%$ Zeonex matrix (Table 2). Compounds M4 show systematically higher $\Phi_{\mathrm{PL}}$ than monocyclic M2 (Table 2), in line with higher oscillator coefficients calculated for M4 (Table S8, ESI). Rigidifying the environment by embedding $\mathbf{M 2}$ in a Zeonex matrix resulted in two-fold intensity increase compared with the solution $\Phi_{\mathrm{PL}}$.

The excited state lifetimes $(\tau)$ for M2 and M4 in toluene (Figure $6 \mathrm{~g}$ ) or methylcyclohexane $(\mathrm{MCH})$ solutions, neat films and films in inert matrices are in the range of $\tau=0.5-16 \mu \mathrm{s}$ with mostly monoexponential decays, which we ascribe to delayed ${ }^{l} C T$ emissions. In solid media the shortest excited state lifetimes decrease in the same order as in solution, $\mathrm{Cu}>\mathrm{Au}>\mathrm{Ag},{ }^{34,43}$ as the net result of the increase in spin-orbit coupling and the HOMO / LUMO overlap integrals (ESI, Table S6). Ag4 has the shortest $\tau$ value (500 ns) and $82 \% \Phi_{\mathrm{PL}}$, resulting in the highest radiative rate among the M2 and M4 complexes, $k_{\mathrm{r}}=1.6 \times 10^{6} \mathrm{~s}^{-1}$, similar to analogous silver CMAs. ${ }^{43} \mathbf{C u} 2$ shows radiative rates (Table 2) of up to one order of magnitude less than the other complexes under various conditions. This further supports the importance of a rigid molecular design to achieve efficient copperbased photoemitters with sub-microsecond excited state lifetimes.

The luminescence decay lifetimes at $77 \mathrm{~K}$ were obtained from mono- and bi-exponential fittings. We ascribe the longest component to the ${ }^{3} L E$ luminescence (Figures 6h, S23, S25), which can be as long as $13 \mathrm{~ms}$ for $\mathbf{C u 2}$, or relatively short (75-274 $\mu$ s) for Au2 and Au4. The shorter decay component we ascribe to ${ }^{3} C T$ excited state lifetimes of 30 to $45 \mu$ s for all M2 and M4. Complexes Au2 and M4 show ${ }^{3} C T$ (77K) lifetimes up to 50 times longer compared with ${ }^{l} C T$ (298K), indicative of a thermally activated emission process. Complex Cu2 exhibits only a 2-3 fold increase in the excited state lifetimes on cooling to $77 \mathrm{~K}$, commensurate with phosphorescence as a major emission mechanism under all conditions.

Time-resolved PL at 298 and $77 \mathrm{~K}$ with various time delays enabled an estimate the ${ }^{3} L E$ energy levels in solid media (Table 2 and ESI, Fig. S26). The majority of the complexes show luminescence profiles with vibronic structure together with a significant contribution of the ${ }^{3} C T$ emission. Unlike MeTHF solutions, in solid matrices the energy of the ${ }^{3} L E$ state is always lower than (up to $0.07 \mathrm{eV}$ ) or similar to the ${ }^{l} C T$ luminescence (Table 2). 
This analysis leads to positive or nearly zero values for the $\triangle E\left({ }^{1} C T-{ }^{3} L E\right)$ energy gap in solid media for all complexes, unlike the negative $\triangle E\left({ }^{1} C T-{ }^{3} L E\right)$ values measured in solution.

\section{- CONCLUSION}

We have demonstrated that electronic (higher ambiphilicity of the carbene) and structural factors (mono- versus bicyclic carbene) provide guidelines for optimizing the photoluminescence properties of CMA emitters. Rigidifying the carbene ligand, securing a linear excited state geometry and choosing metals with high spin-orbit coupling coefficients provides a strategy to minimize non-radiative losses, leading to a combination of unity $\Phi_{\mathrm{PL}}$ with sub-microsecond excited state lifetimes. Rigid matrices suppress the dual luminescence phenomenon from the higher-lying locally excited singlet state $\left({ }^{l} L E, 3.75 \mathrm{eV}\right)$ and improve the charge transfer $(C T)$ emission. We suggest that shorter lifetimes in solution correlate with ${ }^{3} L E$ states being $0.1-0.3 \mathrm{eV}$ higher in energy than ${ }^{I} C T$ states. Optimizing ligand flexibility and aligning the ${ }^{3} L E$ levels above the ${ }^{1} C T /{ }^{3} C T$ manifold in solid media to realize high radiative rates $\left(\geq 1 \times 10^{7} \mathrm{~s}^{-1}\right)$ will be an important molecular design challenge for deepblue CMA materials.

\section{- EXPERIMENTAL SECTION}

Materials and Synthesis. Unless stated otherwise, all reactions were carried out in air. Solvents were distilled and dried as required. Sodium tert-butoxide, carbazole, trivertal was purchased from Sigma-Aldrich. The carbene ligand BIC6, ${ }^{50,51} \mathrm{C}^{49}$ and reported complex Au1 ${ }^{49}$ were obtained according to literature procedures. Supporting information contains detailed synthetic procedures for compounds Cu1, Ag1, M2, M3 and M4.

Materials Characterization. ${ }^{1} \mathrm{H}$ and ${ }^{13} \mathrm{C}\left\{{ }^{1} \mathrm{H}\right\}$ NMR spectra were recorded using a Bruker Avance DPX-300 MHz NMR spectrometer. ${ }^{1} \mathrm{H}$ NMR spectra (300.13 MHz) and ${ }^{13} \mathrm{C}\left\{{ }^{1} \mathrm{H}\right\}(75.47 \mathrm{MHz})$ were referenced to $\mathrm{CD}_{2} \mathrm{Cl}_{2}$ at $\delta$ $5.32\left({ }^{13} \mathrm{C}, \delta\right.$ 53.84) and $\mathrm{CDCl}_{3}$ at $\delta 7.26\left(\delta{ }^{13} \mathrm{C} 77.16\right)$ ppm. All electrochemical experiments were performed using an Autolab PGSTAT 302N computer-controlled potentiostat. Cyclic voltammetry (CV) was performed using a three-electrode configuration consisting of either a glassy carbon macrodisk working electrode (GCE) (diameter of $3 \mathrm{~mm}$; BASi, Indiana, USA) combined with a $\mathrm{Pt}$ wire counter electrode (99.99 \%; GoodFellow, Cambridge, UK) and an Ag wire pseudo-reference electrode (99.99\%; GoodFellow, Cambridge, UK). The GCE was polished between experiments using alumina slurry $(0.3 \mu \mathrm{m})$, rinsed in distilled water and subjected to brief sonication to remove any adhering alumina microparticles. The metal electrodes were then dried in an oven at $100{ }^{\circ} \mathrm{C}$ to remove residual traces of water, the GCE was left to air dry and residual traces of water were removed under vacuum. The Ag wire pseudoreference electrodes were calibrated to the ferrocene/ferrocenium couple in $\mathrm{MeCN}$ at the end of each run to allow for any drift in potential, following IUPAC recommendations. ${ }^{73}$ All electrochemical measurements were performed at ambient temperatures under an inert Ar atmosphere in THF containing complex under study $(0.14 \mathrm{mM})$ and supporting electrolyte $\left[\mathrm{n}-\mathrm{Bu}_{4} \mathrm{~N}\right]\left[\mathrm{PF}_{6}\right](0.13 \mathrm{mM})$. Data were recorded with Autolab NOVA software (v. 1.11). Elemental analyses were performed by London Metropolitan University. UV-visible absorption spectra were recorded using a Perkin-Elmer Lambda $35 \mathrm{UV} / \mathrm{vis}$ spectrometer. Mass spectrometry data was obtained using APCI(ASAP) (Atmospheric Solids Analysis Probe) at the National Mass Spectrometry Facility at Swansea University.

\section{- ASSOCIATED CONTENT}

CCDC number for Cu1 (1970649), Cu2 (1970647), Cu3 (1970652), Cu4 (1970653), Ag1 (1970646), Ag4 (1970650), Au2 (1970648) and Au4 (1970651) for the crystallographic data via The Cambridge Crystallographic Data Centre www.ccdc.cam.ac.uk/data request/cif. Detailed experimental procedures, single-crystal X-ray diffraction data, electrochemistry, photophysical and computational details. The Supporting Information is available free of charge on the ACS Publications website at DOI: 10.1039/XXXXXX.

\section{- AUTHOR INFORMATION}

\section{Corresponding Author}

*E-mail: a.romanov@uea.ac.uk

*E-mail: mikko.linnolahti@uef.fi

*E-mail: m.bochmann@uea.ac.uk

ORCID ID

Dr. Florian Chotard https://orcid.org/0000-0002-4791-5270

Dr. Vasily Sivchik https://orcid.org/0000-0003-3761-6661

Prof. Dr. M. Linnolahti https://orcid.org/0000-0003-00562698

Prof. Dr. M. Bochmann: https://orcid.org/0000-0001-77365428

Dr. A. S. Romanov: https://orcid.org/0000-0003-2617-6402

\section{Author Contributions}

The manuscript was written through contributions of all authors. All authors have given approval to the final version of the manuscript.

Notes

There are no conflicts to declare.

\section{- ACKNOWLEDGMENT}

A. S. R. acknowledges support from the Royal Society (grant nos. URF $\backslash \mathrm{R} 1 \backslash 180288$ and RGF $\backslash \mathrm{EA} \backslash 181008)$. M. B. is an ERC Advanced Investigator Award holder (grant no. 338944GOCAT). We are grateful to Samsung Display Corp. for support. The computations were made possible by use of the Finnish Grid and Cloud Infrastructure resources (urn:nbn:fi:research-infras-2016072533). M. L. acknowledges the Academy of Finland Flagship Programme, Photonics Research and Innovation (PREIN), decision 320166. We are grateful to ZEON EUROPE GmbH for providing ZEONEX® 480 Cyclo Olefin Polymer (COP) used in our studies.

\section{ABBREVIATIONS}

CMA, carbene-metal-amide; PL, photoluminescence; $\Phi_{\mathrm{PL}}$, absolute photoluminescence quantum yield; MS, mass spectrometry; CT, charge transfer; TADF, thermally activated delayed fluorescence.

\section{- REFERENCES}


(1) Ford, P. C.; Vogler, A. Photochemical and photophysical properties of tetranuclear and hexanuclear clusters of metals with $\mathrm{d}^{10}$ and $\mathrm{s}^{2}$ electronic configurations Acc. Chem. Res. 1993, 26, 220-226.

(2) Balzani, V.; Juris, A.; Venturi, M.; Campagna, S.; Serroni, S. Luminescent and Redox-Active Polynuclear Transition Metal Complexes. Chem. Rev. 1996, 96, 759834.

(3) McMillin, D. R.; McNett, K. M. Photoprocesses of copper complexes that bind to DNA. Chem. Rev. 1998, 98, 1201-1219.

(4) Cuttell, D. G.; Kuang, S.-M.; Fanwick, P. E.; McMillin, D. R.; Walton, R. A. Simple $\mathrm{Cu}(\mathrm{I})$ complexes with unprecedented excited-state lifetimes. J. Am. Chem. Soc. 2002, 124, 6-7.

(5) Armaroli, N.; Accorsi, G.; Cardinali, F.; Listorti, A. Photochemistry and Photophysics of Coordination Compounds: Copper. Top. Curr. Chem. 2007, 280, 69-115. (6) Harkins, S. B.; Peters, J. C., A highly emissive $\mathrm{Cu}_{2} \mathrm{~N}_{2}$ diamond core complex supported by a [PNP]- ligand. J. Am. Chem. Soc. 2005, 127, 2030-2031.

(7) Visbal, R.; Gimeno, M. C., N-heterocyclic carbene metal complexes: photoluminescence and applications. Chem. Soc. Rev. 2014, 43, 3551-3574.

(8) Yersin, H.; Czerwieniec, R.; Shafikov, M. Z.; Suleymanova A. F., TADF material design: photophysical background and case studies focusing on $\mathrm{CuI}$ and $\mathrm{AgI}$ complexes. ChemPhysChem., 2017, 18, 3508-3535.

(9) Bizzarri, C.; Spuling, E.; Knoll, D. M.; Volz, D.; Bräse, S., Sustainable metal complexes for organic light-emitting diodes (OLEDs). Coord. Chem. Rev. 2018, 373, 49-82.

(10) Che, C. M.; Wong, W. T.; Lai, T. F.; Kwong, H. L. Novel luminescent binuclear gold(I) isocyanide complexes. Synthesis, spectroscopy, and X-ray crystal structure of $\mathrm{Au}_{2}(\mathrm{dmb})(\mathrm{CN})_{2}(\mathrm{dmb}=1,8$-di-isocyano-p-menthane $) . \quad J$. Chem. Soc. Chem. Commun. 1989, 4, 243-244.

(11) Forward, J. M.; Bohmann, D.; Fackler Jr., J. P.; Staples, R. J. Luminescence Studies of Gold (I) Thiolate Complexes. Inorg. Chem. 1995, 34, 6330-6336.

(12) Harrison, M. J. W.; Chen, C. Y. L.; Lin, I. J. B. Synthesis, Structure, and Spectroscopic Properties of Gold(I)-Carbene Complexes. Organometallics 1999, 18, 1216-1223.

(13) Catalano, V.J.; Moore, A. L. Mono-, Di-, and Trinuclear Luminescent Silver(I) and Gold(I) NHeterocyclic Carbene Complexes Derived from the PicolylSubstituted Methylimidazolium Salt: 1-Methyl-3-(2pyridinylmethyl)-1H-imidazolium Tetrafluoroborate. Inorg. Chem. 2005, 44, 6558-6566.

(14) Krylova, V. A.; Djurovich, P. I.; Whited M. T.; Thompson, M. E. Synthesis and characterization of phosphorescent three-coordinate $\mathrm{Cu}(\mathrm{I})-\mathrm{NHC}$ complexes. Chem. Commun. 2010, 46, 6696-6698.

(15) Krylova, V. A.; Djurovich, P. I.; Conley, B. L.; Haiges, R.; Whited, M. T.; Williams, T. J.; Thompson, M. E. Control of emission colour with N-heterocyclic carbene (NHC) ligands in phosphorescent three-coordinate $\mathrm{Cu}(\mathrm{I})$ complexes. Chem. Commun. 2014, 50, 7176-7179.

(16) Marion, R.; Sguerra, F.; Di Meo, F.; Sauvageot, E.; Lohier, J.-F.; Daniellou, R.; Renaud, J.-L.; Linares, M.; Hamel, M.; Gaillard, S. NHC Copper(I) Complexes Bearing Dipyridylamine Ligands: Synthesis, Structural, and
Photoluminescent Studies. Inorg. Chem. 2014, 53, 91819191.

(17) Yersin, H. (ed.), Highly Efficient OLEDs with Phosphorescent Materials. 2008 WILEY-VCH ISBN: 9783-527-40594-7.

(18) Yersin H. (ed.), Highly Efficient OLEDs - Materials Based on Thermally Activated Delayed Fluorescence. Wiley-VCH, Weinheim, 2019. ISBN: 978-3-527-33900-6.

(19) Romanov, A. S.; Di, D.; Yang, L.; Fernandez-Cestau, J.; Becker, C. R.; James, C. E.; Zhu, B.; Linnolahti, M.; Credgington, D.; Bochmann, M. Highly photoluminescent copper carbene complexes based on prompt rather than delayed fluorescence. Chem. Commun. 2016, 52, 6379.

(20) Romanov, A. S.; Di, D.; Yang, L.; Fernandez-Cestau, J.; Becker, C. R.; James, C. E.; Zhu, B.; Linnolahti, M.; Credgington, D.; Bochmann, M. Correction: Highly photoluminescent copper carbene complexes based on prompt rather than delayed fluorescence. Chem. Commun. 2018, 54, 3672-3672.

(21) Romanov, A. S.; Becker, C. R.; James, C. E.; Di, D.; Credgington, D.; Linnolahti, M.; Bochmann, M. Copper and Gold Cyclic (Alkyl)(amino)carbene Complexes with Sub-Microsecond Photoemissions: Structure and Substituent Effects on Redox and Luminescent Properties. Chem. - Eur. J. 2017, 23, 4625-4637.

(22) Romanov, A. S.; Bochmann, M. Synthesis, structures and photoluminescence properties of silver complexes of cyclic (alkyl)(amino)carbenes. J. Organomet. Chem. 2017, $847,114-120$.

(23) M. Gernert, U. Müller, M. Haehnel, J. Pflaum, A. Steffen. A Cyclic Alkyl(amino)carbene as Two-Atom $\pi$ Chromophore Leading to the First Phosphorescent Linear $\mathrm{Cu}^{\mathrm{I}}$ Complexes. Chem. - Eur. J., 2017, 23, 2206-2216.

(24) Di, D.; Romanov, A. S.; Yang, L.; Richter, J. M.; Rivett, J. P. H.; Jones, S.; Thomas, T. H.; Jalebi, M. A.; Friend, R. H.; Linnolahti, M.; Bochmann, M.; Credgington, D. High-performance light-emitting diodes based on carbene-metal-amides. Science 2017, 356, 159-163.

(25) Conaghan, P. J.; Matthews, C. S. B.; Chotard, F.; Jones, S. T. E.; Greenham, N. C.; Bochmann, M.; Credgington, D.; Romanov, A. S. Highly efficient blue organic light-emitting diodes based on carbene-metalamides. Nature Commun. 2020, 11, 1758.

(26) Romanov, A. S.; Chotard, F.; Rashid, J.; Bochmann, M. Synthesis of copper(I) cyclic (alkyl)(amino)carbene complexes with potentially bidentate $\mathrm{N}^{\wedge} \mathrm{N}, \mathrm{N}^{\wedge} \mathrm{S}$ and $\mathrm{S}^{\wedge} \mathrm{S}$ ligands for efficient white photoluminescence. Dalton Trans. 2019, 48, 15445-15454.

(27) Chotard, F.; Romanov, A. S.; Hughes, D. L.; Linnolahti, M.; Bochmann, M. Zwitterionic Mixed-Carbene Coinage Metal Complexes: Synthesis, Structures, and Photophysical Studies. Eur. J. Inorg. Chem. 2019, 42344240 .

(28) Feng, J.; Yang, L.; Romanov, A. S.; Ratanapreechachai, J.; Jones, S. T. E.; Reponen, A. P. M.; Linnolahti, M.; Hele, T. J. H.; Köhler, A.; Bässler, H.; Bochmann, M.; Credgington, D. Environmental Control of Triplet Emission in Donor-Bridge-Acceptor Organometallics. Adv. Funct. Mater. 2020, 30, 1908715.

(29) Feng, J.; Taffet, E. J.; Reponen, A. P. M.; Romanov, A. S.; Olivier, Y.; Lemaur, V.; Yang, L.; Linnolahti, M.; Bochmann, M.; Beljonne, D.; Credgington, D. Carbene-Metal-Amide Polycrystalline Materials Feature 
Blue Shifted Energy yet Unchanged Kinetics of Emission. Chem. Mater., 2020, https://doi.org/10.1021/acs.chemmater.0c01363 (accepted manuscript).

(30) Lavallo, V.; Canac, Y.; DeHope, A.; Donnadieu, B.; Bertrand, G. A Rigid Cyclic (Alkyl)(amino)carbene Ligand Leads to Isolation of Low-Coordinate Transition-Metal Complexes. Angew. Chem. Int. Ed. 2005, 44, 7236-7239;

(31) Soleilhavoup M.; Bertrand, G. Cyclic (Alkyl)(Amino)Carbenes (CAACs): Stable Carbenes on the Rise. Acc. Chem. Res. 2015, 48, 256-266.

(32) Melaimi, M.; Jazzar, R.; Soleilhavoup, M.; Bertrand, G. Cyclic (Alkyl)(amino)carbenes (CAACs): Recent Developments. Angew. Chem. Int. Ed. 2017, 56, 1004610068.

(33) Conaghan, P. J.; Menke, S. M.; Romanov, A. S.; Pearson, A. J.; Evans, E. W.; Bochmann, M.; Greenham, N. C.; Credgington, D. Efficient Vacuum-Processed Light-Emitting Diodes Based on Carbene-Metal-Amides. Adv. Mater. 2018, 30, 1802285.

(34) Romanov, A. S.; Jones, S. T. E.; Yang, L.; Conaghan, P. J.; Di, D.; Linnolahti, M.; Credgington, D.; Bochmann, M. Mononuclear Silver Complexes for Efficient Solution and Vacuum-Processed OLEDs. Adv. Optical Mater. 2018, 6,1801347

(35) Romanov, A. S.; Yang, L.; Jones, S. T. E.; Di, D.; Morley, O. J.; Drummond, B.; Reponen, A. P. M.; Linnolahti, M.; Credgington, D.; Bochmann, M. Dendritic Carbene Metal Carbazole Complexes as Photoemitters for Fully Solution-Processed OLEDs. Chem. Mater. 2019, 31, 3613-3623.

(36) Romanov, A. S.; Jones, S. T. E.; Gu, Q.; Conaghan, P. J.; Drummond, B. H.; Feng, J.; Chotard, F.; Buizza, L.; Foley, M.; Linnolahti, M.; Credgington, D.; Bochmann, M. Carbene metal amide photoemitters: tailoring conformationally flexible amides for full color range emissions including white-emitting OLED. Chem. Sci. 2020, 11, 435-446.

(37) Hamze, R.; Peltier, J. L.; Sylvinson, D.; Jung, M.; Cardenas, J.; Haiges, R.; Soleilhavoup, M.; Jazzar, R.; Djurovich, P. I.; Bertrand, G.; Thompson, M. E. Eliminating nonradiative decay in $\mathrm{Cu}(\mathrm{I})$ emitters: $>99 \%$ quantum efficiency and microsecond lifetime. Science 2019, 363, 601-606.

(38) Hamze, R.; Jazzar, R.; Soleilhavoup, M.; Djurovich, P. I.; Bertrand, G.; Thompson, M. E. Phosphorescent 2-, 3and 4-coordinate cyclic (alkyl)(amino)carbene (CAAC) $\mathrm{Cu}(\mathrm{I})$ complexes. Chem. Commun. 2017, 53, 9008-9011.

(39) Hudnall, T. W.; Bielawski, C. W. An N,N'Diamidocarbene: Studies in $\mathrm{C}-\mathrm{H}$ Insertion, Reversible Carbonylation, and Transition-Metal Coordination Chemistry. J. Am. Chem. Soc. 2009, 131, 16039-16041.

(40) Blake, G. A.; Moerdyk, J. P.; Bielawski, C. W. Novel Expanded Ring N-Heterocyclic Carbenes: Free Carbenes, Silver Complexes, And Structures. Organometallics 2012, 31, 3373-3378.

(41) Shi, S.; Collins, L. R.; Mahon, M. F.; Djurovich, P.; Thompson M. E.; Whittlesey, M. K. Synthesis and characterization of phosphorescent two-coordinate copper(I) complexes bearing diamidocarbene ligands. Dalton Trans. 2017, 46, 745-752.

(42) Shi, S.; Jung, M. C.; Coburn, C.; Tadle, A.; Sylvinson D. M. R.; Djurovich, P. I.; Forrest, S. R.; Thompson, M. E.
Highly Efficient Photo- and Electroluminescence from Two-Coordinate $\mathrm{Cu}(\mathrm{I}) \quad$ Complexes Featuring Nonconventional N-Heterocyclic Carbenes. J. Am. Chem. Soc. 2019, 141, 3576-3588.

(43) Hamze, R.; Shi, S.; Kapper, S. C.; Ravinson, D. S. M.; Estergreen, L.; Jung, M.-C.; Tadle, A. C.; Haiges, R.; Djurovich, P. I.; Peltier, J. L.; Jazzar, R.; Bertrand, G.; Bradforth S. E.; Thompson, M. E. "Quick-Silver" from a Systematic Study of Highly Luminescent, Two-Coordinate, $\mathrm{d}^{10}$ Coinage Metal Complexes. J. Am. Chem. Soc. 2019, 141, 8616-8626.

(44) Gernert, M.; Balles-Wolf, L.; Kerner, F.; Müller, U.; Schmiedel, A.; Holzapfel, M.; Marian, C. M.; Pflaum, J.; Lambert, C.; Steffen, A. Cyclic (amino)(aryl)carbenes (CAArCs) enter the field of chromophore ligands Expanded $\pi$ system leads to unusually deep red emitting $\mathrm{Cu}^{\mathrm{I}}$ compounds. J. Am. Chem. Soc. 2020, accepted. DOI: 10.1021 /jacs.0c02234.

(45) Föller, J.; Marian, C. M. Rotationally Assisted SpinState Inversion in Carbene-Metal-Amides Is an Artifact. $J$. Phys. Chem. Lett. 2017, 8, 5643-5647.

(46) Taffet, E. J.; Olivier, Y.; Lam, F.; Beljonne, D.; Scholes, G. D. Carbene-Metal-Amide Bond Deformation, Rather Than Ligand Rotation, Drives Delayed Fluorescence. J. Phys. Chem. Lett. 2018, 9, 1620-1626.

(47) Thompson, S.; Eng, J.; Penfold, T. J. The intersystem crossing of a cyclic (alkyl)(amino) carbene gold (I) complex. J. Chem. Phys. 2018, 149, 014304.

(48) Hall, C. R.; Romanov, A. S.; Bochmann, M.; Meech, S. R. Ultrafast Structure and Dynamics in the Thermally Activated Delayed Fluorescence of a Carbene-MetalAmide. J. Phys. Chem. Lett. 2018, 9(19), 5873-5876.

(49) Weinstein, C. M.; Junor, G. P.; Tolentino, D. R.; Jazzar, R.; Melaimi, M.; Bertrand, G. Highly Ambiphilic Room Temperature Stable Six-Membered Cyclic (Alkyl)(amino)carbenes. J. Am. Chem. Soc. 2018, 140(29), 9255-9260.

(50) Tomás-Mendivil, E.; Hansmann, M. M.; Weinstein, C. M.; Jazzar, R.; Melaimi, M.; Bertrand, G. Bicyclic (Alkyl)(amino)carbenes (BICAACs): Stable Carbenes More Ambiphilic than CAACs. J. Am. Chem. Soc. 2017, 139, 7753-7756.

(51) Yazdani, S.; Junor, G. P.; Peltier, J. L.; Gembicky, M.; Jazzar, R.; Grotjahn, D. B.; Bertrand, G. Influence of Carbene and Phosphine Ligands on the Catalytic Activity of Gold Complexes in the Hydroamination and Hydrohydrazination of Alkynes. ACS Catal. 2020, 10, 5190-5201.

(52) Bayler, A.; Schier, A.; Bowmaker, G. A.; Schmidbaur, H. Gold Is Smaller than Silver. Crystal Structures of [Bis(trimesitylphosphine)gold(I)] and [Bis(trimesitylphosphine)silver(I)] Tetrafluoroborate. $J$. Am. Chem. Soc. 1996, 118, 7006-7007.

(53) Osawa, M.; Hoshino, M.; Hashimoto, M.; Kawata, I.; Igawa S.; Yashima, M. Application of three-coordinate copper(I) complexes with halide ligands in organic lightemitting diodes that exhibit delayed fluorescence. Dalton Trans. 2015, 44, 8369-8378.

(54) Hashimoto, M.; Igawa, M.; Yashima, M.; Kawata, I.; Hoshino M.; Osawa, M. Highly Efficient Green Organic Light-Emitting Diodes Containing Luminescent ThreeCoordinate Copper(I) Complexes. J. Am. Chem. Soc. 2011, 133, 10348-10351. 
(55) Falivene, L.; Cao, Z.; Petta, A.; Serra, L.; Poater, A.; Oliva, R.; Scarano, V.; Cavallo, L., Towards the online computer-aided design of catalytic pockets. Nat. Chem. 2019, 11(10), 872-879.

(56) Eggleston, M. K.; McMillin, D. R.; Koenig K. S.; Pallenberg, A. J. Steric Effects in the Ground and Excited States of $\mathrm{Cu}(\mathrm{NN})^{2+}$. Systems Inorg. Chem. 1997, 36, 172176.

(57) Siddique, Z. A.; Yamamoto, Y.; Ohno, T.; Nozaki, K. Structure-Dependent Photophysical Properties of Singlet and Triplet Metal-to-Ligand Charge Transfer States in Copper(I) Bis(diimine) Compounds. Inorg. Chem. 2003, 42(20), 6366-6378.

(58) Linfoot, C. L.; Leitl, M. J.; Richardson, P.; Rausch, A. F.; Chepelin, O.; White, F. J.; Yersin H.; Robertson, N. Thermally Activated Delayed Fluorescence (TADF) and Enhancing Photoluminescence Quantum Yields of $\left[\mathrm{CuI}(\text { diimine)(diphosphine) }]^{+}\right.$Complexes - Photophysical, Structural, and Computational Studies. Inorg. Chem. 2014, $53,10854-10861$.

(59) McMillin, D. R.; McNett, K. M. Photoprocesses of Copper Complexes That Bind to DNA. Chem. Rev. 1998, 98(3), 1201-1220.

(60) Reddy, P. V. G.; Tabassum, S.; Blanruea A.; Wilhelm, R. New enantiopure NHCs derived from camphor. Chem. Commun. 2009, 5910-5912.

(61) Sampford, K. R.; Carden, J. L.; Kidner, E. B.; Berry, A.; Cavell, K. J.; Murphy, D. M.; Kariuki B. M.; Newman, P. D. Twisting the arm: structural constraints in bicyclic expanded-ring N-heterocyclic carbenes. Dalton Trans. 2019, 48, 1850-1858.

(62) Varied-temperature ${ }^{1} \mathrm{H}$ NMR spectra for $\mathbf{C u} 2$ and $\mathbf{C u} 4$ complexes in DCM- $\mathrm{d}^{2}$ solution show that energy barrier is too low to resolve the conformational behavior in the temperature range from +20 to $-80^{\circ} \mathrm{C}$, see Figure $\mathrm{S} 41$.

(63) Lin, S.; Peng, Q.; Ou, Q.; Shuai, Z. Strong Solid-State Fluorescence Induced by Restriction of the Coordinate Bond Bending in Two-Coordinate Copper(I)-Carbene Complexes. Inorg. Chem. 2019, 58, 14403-14409.

(64) Li, T.-Y.; Sylvinson, D.; Ravinson, M.; Haiges, R.; Djurovich, P. I.; Thompson, M. E. Enhancement of the Luminescent Efficiency in Carbene-Au(I)-Aryl Complexes by the Restriction of Renner-Teller Distortion and Bond Rotation. J. Am. Chem. Soc. 2020, 142, 6158-6172.

(65) Penfold, T. J.; Dias, F. B.; Monkman, A. P. The theory of thermally activated delayed fluorescence for organic light emitting diodes. Chem. Commun. 2018, 54, 39263935.

(66) Penfold, T. J.; Gindensperger, E.; Daniel, C.; Marian, C. M. Spin-Vibronic Mechanism for Intersystem Crossing. Chem. Rev. 2018, 118, 6975-7025.

(67) Silva, P. de; Kim, C. A.; Zhu, T.; Van Voorhis, T. Extracting Design Principles for Efficient Thermally Activated Delayed Fluorescence (TADF) from a Simple Four-State Model. Chem. Mater. 2019, 31, 6995-7006.

(68) Kozhevnikov, D. N.; Kozhevnikov, V. N.; Shafikov, M. Z.; Prokhorov, A. M.; Bruce, D. W.; Williams, J. A. G. Phosphorescence vs Fluorescence in Cyclometalated Platinum(II) and Iridium(III) Complexes of (Oligo)thienylpyridines. Inorg. Chem. 2011, 50, 3804-3815.

(69) Kisel, K. S.; Eskelinen, T.; Zafar, W.; Solomatina, A. I.; Hirva, P.; Grachova, E. V.; Tunik, S. P.; Koshevoy, I. O. Chromophore-Functionalized Phenanthro-diimine Ligands and
Their $\operatorname{Re}(\mathrm{I})$ Complexes. Inorg. Chem. 2018, 57, 6349-6361. (70) Jacquemin, D.; Escudero, D. Thermal equilibration between excited states or solvent effects: unveiling the origins of anomalous emissions in heteroleptic Ru(II) complexes. Phys. Chem. Chem. Phys. 2018, 20, 11559-11563.

(71) Demchenko, A. P.; Tomin, V. I.; Chou, P.-T. Breaking the Kasha Rule for More Efficient Photochemistry. Chem. Rev. 2017, 117, 13353-13381.

(72) Röhrs, M. Escudero, D. Multiple Anti-Kasha Emissions in Transition-Metal Complexes. J. Phys. Chem. Lett. 2019, 10, 5798-5804.

(73) Gritzner, G.; Kůta, J. Recommendations on reporting electrode potentials in nonaqueous solvents: IUPC commission on electrochemistry. Electrochim. Acta 1984, 29, 869-873. 
Insert Table of Contents artwork here

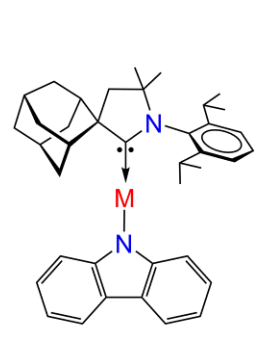

Previous work:

$\Phi_{\mathrm{PL}}$ up to $98 \%$

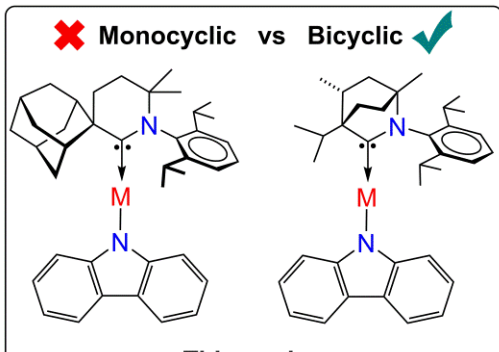

This work:

$\Phi_{\mathrm{PL}}$ up to $50 \% \quad \Phi_{\mathrm{PL}}$ up to $100 \%$ 